\begin{tabular}{lcl}
\hline Bentham OPEN & The Open Orthopaedics Journal \\
CrossMark & Content list available at: www.benthamopen.com/TOORTHJ/ & DOI: $10.2174 / 1874325001610010277$ \\
\hline
\end{tabular}

REVIEW ARTICLE

\title{
Risk Factors, Pathobiomechanics and Physical Examination of Rotator Cuff Tears
}

\author{
Samuel G. Moulton ${ }^{1}$, Joshua A. Greenspoon ${ }^{1}$, Peter J. Millett ${ }^{1,2 *}$ and Maximilian Petri ${ }^{1,2}$

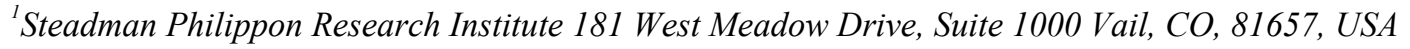 \\ ${ }^{2}$ The Steadman Clinic, 181 West Meadow Drive Vail, CO, 81657, USA
}

Received: July 16, 2015

Revised: July 21, 2015

Accepted: February 1, 2016

\begin{abstract}
:
Background:

It is important to appreciate the risk factors for the development of rotator cuff tears and specific physical examination maneuvers.

Methods:

A selective literature search was performed.

Results:

Numerous well-designed studies have demonstrated that common risk factors include age, occupation, and anatomic considerations such as the critical shoulder angle. Recently, research has also reported a genetic component as well. The rotator cuff axially compresses the humeral head in the glenohumeral joint and provides rotational motion and abduction. Forces are grouped into coronal and axial force couples. Rotator cuff tears are thought to occur when the force couples become imbalanced.
\end{abstract}

\section{Conclusion:}

Physical examination is essential to determining whether a patient has an anterosuperior or posterosuperior tear. Diagnostic accuracy increases when combining a series of examination maneuvers.

Keywords: Force couples, Natural history, Pathobiomechanics, Physical examination, Risk factors, Rotator cuff tear, Shoulder, Shoulder joint.

\section{INTRODUCTION}

Rotator cuff tears include a variety of tear sizes, tear locations, and associated pathology. Patients may present with a spectrum of findings from no pain to severe shoulder pain and normal function to severe dysfunction. Recent biomechanical and clinical research has improved our understanding of the complexity of rotator cuff tears, including risk factors associated with certain tear patterns and tear progression as well as the biomechanical consequences of rotator cuff tears. Specifically, studies investigating risk factors of rotator cuff tears have demonstrated the importance of factors such as age, muscle quality, and tear size on long-term patient outcomes. By understanding risk factors associated with symptoms of rotator cuff tears and tear progression, indications for surgical management can be refined to improve patient selection and ultimately patient outcomes.

Additionally, physical examination is essential to forming the correct diagnosis and plan. Specific physical examination maneuvers can help identify the location and extent of rotator cuff tears. A variety of maneuvers are

\footnotetext{
* Address correspondence to this author at the Steadman Philippon Research Institute, 181 West Meadow Drive, Suite 1000 Vail, CO, 81657, USA; E-mail: drmillett@thesteadmanclinic.com
} 
reported in the literature, however certain maneuvers have been demonstrated to have better diagnostic accuracy. The purpose of this paper is to review risk factors associated with the development and progression of rotator cuff tears, present a pathobiomechanical understanding of rotator cuff tears, and present the diagnostic accuracies of specific physical examination maneuvers.

\section{RISK FACTORS}

The overall prevalence of rotator cuff tears is difficult to quantify $[1,2]$. However, the prevalence of rotator cuff disease does increase with age [3], with one estimate that $22 \%$ of patients 65 years or older have full-thickness rotator cuff tears [4, 5]. Yamaguchi et al. demonstrated this association in their series of 588 consecutive patients who presented with unilateral shoulder pain [6]. All 588 patients were evaluated by ultrasound for the appearance and extent of rotator cuff disease bilaterally. They found that the average age for patients with no rotator cuff tear was 48.7 years, while the average age for unilateral tears was 58.7 years and 67.8 years for patients with bilateral rotator cuff tears. Additionally, there was a 50\% likelihood of a bilateral tear in patients older than 66 years of age. It is important to note that these results only represent the symptomatic patient population. Tempelhof et al. investigated the prevalence of rotator cuff tears in asymptomatic patients and found the same relationship with age [7]. Among 411 asymptomatic patients, $23 \%$ had evidence of a rotator cuff tear on ultrasound. When broken down into age groups, $13 \%(22$ of 167$)$ were between the age of 50 to 59 years, $20 \%$ (22 of 108) were between the age of 60 to 69 years, $31 \%(22$ of 87$)$ were between the age of 70 to 79 , and $51 \%$ (25 of 49) were greater than 80 years old.

Numerous studies have investigated risk factors associated with the progression of asymptomatic tears into symptomatic tears requiring treatment [8 - 11]. One common risk factor for symptomatic progression is tear size. Mall et al. followed 195 patients with asymptomatic rotator cuff tears annually [9]. They reported that pain development was associated with increase in tear size, as $40 \%$ of partial thickness tears progressed to full thickness tears in cases of newfound pain. Moosmayer et al. reported similar results in 50 patients with initially asymptomatic full-thickness tears [8]. They found at 3-year follow-up, mean tear size was significantly larger $(10 \mathrm{~mm})$ in newly symptomatic patients compared to the still asymptomatic patients $(3.3 \mathrm{~mm})$. Additionally, they reported that advanced muscle atrophy and fatty degeneration were also associated with pain development. Finally, Keener et al. recently reported that the risk of tear enlargement and muscle degeneration was greater in patients with full-thickness rotator cuff tears compared to partial-thickness tears, in their evaluation of 224 patients at an average of 5.1 years [10].

Additionally, a patient's occupation is a risk factor for both rotator cuff tears and failure after rotator cuff repairs. Occupations involving repetitive overhead lifting places stresses on the rotator cuff, which can ultimately lead to tearing. Namdari et al. investigated factors associated with poor outcomes following structural failure of rotator cuff repair on ultrasound [11]. Patients were retrospectively categorized as having poor outcomes based on postoperative American Shoulder and Elbow Surgeons (ASES) scores less than 80, while successful outcomes were considered as ASES scores $\geq 80$. Of the 28 patients with poor outcomes, 15 reported labor-intensive occupations. Only 2 of the 33 patients with successful outcomes reported labor-intensive occupations. No other demographic factor significantly differed between the two groups. The authors concluded that labor-intensive occupations posed a significant risk factor to patient outcomes.

While demographic factors such as age or occupation have been well cited as risk factors associated with the prevalence of rotator cuff tears, recent attention has turned to genetic factors [12 - 14]. Initial studies focused on the prevalence of rotator cuff tears among family members. Harvie et al. retrospectively reviewed 205 cases of fullthickness rotator cuff tears and determined the prevalence of rotator cuff tears in 129 siblings with ultrasound and compared to spouses as non-genetically related controls [13]. They demonstrated that the relative risk of symptomatic full thickness tears was 4.65 time greater in siblings compared to spouses.

Recent studies have investigated this phenomenon at the genetic level, demonstrating the association of various genetic polymorphisms associated with rotator cuff disease. Motta et al. demonstrated that polymorphisms in genes, which express proteins associated with tendon healing and repair or conversely those associated with muscle and tendon degradation are associated with rotator cuff disease [14]. One important class of proteins involved in muscle and tendon degradation are the defensins. Motta et al. found that a genetic polymorphism in the $D E F B 1$ gene, which encodes the human $\beta$-defensin 1 protein was associated with rotator cuff disease. Additionally, genes encoding proteins involved in tendon repair were also associated with rotator cuff disease, including $H I F 1$ and ESRB, which are associated with regulation of the adaptive response to hypoxia and $F G F 3, F G F 10$, and $F G F R 1$, which are all a part of the fibroblast cytokine family known for collagen production and turnover during tendon healing. These preliminary genetic studies 
demonstrate the local inherent biology of the rotator cuff may pose a role in disease and healing.

Anatomic differences are also risk factors for rotator cuff tears. The crictical shoulder angle (CSA) is one anatomic risk factor [15]. The CSA is measured on true anteroposterior radiographs by forming a line between the inferior and superior margins of the glenoid fossa and second line between the inferior margin of the glenoid fossa and the inferior lateral point of the acromion process. Moor et al. analyzed the CSA of 607 shoulders of patients 40 years or older and they found that a larger CSA was an independent predictor for a posterosuperior rotator cuff tears [16]. Biomechanically, Gerber et al. demonstrated that a larger CSA increases the instability ratio (the ratio of join shear force to joint compression force) [17]. The supraspinatus tendon is overloaded in response to the increased instability, especially at lower angles of abduction, which may eventually lead to a posterosuperior rotator cuff tear.

The size and morphology of the acromion process are additional anatomic risk factors associated with rotator cuff disease [17 - 19]. Nyffeler et al. demonstrated in 102 patients that the average acromion index (the distance from the lateral border of the acromion to the glenoid plane divided by the distance from the lateral border of the humeral head to the glenoid plane) was significantly larger in patients with full-thickness rotator cuff tears $(0.73)$ compared to patients with intact rotator cuffs [19]. Acromial morphology is also an important risk factor. Acromial morphology is separated by the Bigliani classification into 3 types: type 1 is flat, type 2 is curved, and type 3 is hooked. In Bigliani's original study, he and his colleagues found rotator cuff tears in 70\% of cadavers with type 3 acromions [20].

Further studies are needed to improve our understanding of the genetic basis of rotator cuff disease, which may eventually lead one day to targeted molecular therapies for rotator cuff tears.

\section{PATHOBIOMECHANICS}

The muscles of the rotator cuff work with the deltoid to maintain stability of the glenohumeral joint, allowing for normal function. Generally, the rotator cuff has two important functions: axial compression of the humeral head and generating torque for humeral head rotation. In 1991, Burkhart introduced the force couple concept to describe the biomechanical function of the rotator cuff [21]. When abduction is initiated, the coronal force couple composed of the supraspinatus and the deltoid compresses the humeral head into the glenoid [22]. The axial force couple, composed of the subscapularis and infraspinatus, provides joint stability with compressive forces in the axial plane. Burkhart concluded that the balance of the axial and coronal force couples is essential for normal glenohumeral kinematics [21]. Rotator cuff tears can disrupt these force couples, even partial tears, leading to larger tears and significant functional impairments.

Burkhart introduced the suspension bridge model and the rotator cable concept in 1993 [23]. The rotator cable describes a thickened layer of tendon that covers the supraspinatus and infraspinatus tendons. The thickened rotator cable allows dispersion of the tendon forces along the length of the cable. The rotator cable surrounds an area of tendon known as the rotator crescent, which is protected from the strong forces of the supraspinatus and infraspinatus tendons. Together, the force couple concept and the suspension bridge model offer an explanation as to why certain patients with structurally deficient rotator cuffs remain asymptomatic. As long as the axial and coronal force couples remained balanced, in part by the dispersion of forces across the rotator cable, structurally deficient rotator cuffs may remain stable and pain-free.

Rotator cuff tears can be grouped into either posterosuperior tears or anterosuperior tears [24]. Posterosuperior tears involve disruption of the supraspinatus and infraspinatus tendons, and sometimes extend into the teres minor. On the other hand, anterosuperior tears involve tears of the supraspinatus and the subscapularis tendons. When rotator cuff tears involve the posterosuperior tendons, the deltoid and remaining intact muscle tendons must exert increasing forces to the achieve stable abduction [25]. If the axial force couple is disrupted, superior migration of the humeral head is common [22]. The increase in forces exerted by the remaining rotator cuff tendons can contribute to tear propagation and extension. In addition, the loss of glenohumeral stability leads to eccentrically applied loads to the glenoid and abnormal wear patterns may develop and contribute to arthritic changes in the shoulder. The rationale behind surgical intervention is to restore the force couples of the rotator cuff, thereby improving shoulder function and preventing further arthritic changes.

Pain can be caused by a variety of factors such as tendinopathy, superior migration, and long head biceps tendon instability. Inflammation of any of the rotator cuff tendons can be a source of shoulder pain, often requiring steroid injections or plasma rich protein (PRP) injections [26]. Superior migration occurs when at least two of the rotator cuff tendons are torn, allowing the humeral head to migrate superiorly often producing pain [27]. Finally, biceps instability 
is another cause of shoulder pain requiring surgical management. A systematic review by Creech et al. concluded that long head of the biceps pain was a common indication for biceps tenodesis [28].

\section{PHYSICAL EXAMINATION}

Physical examination is a pivotal component in assessing patients presenting with potential rotator cuff pathology. The shoulder examination can be helpful in refining the initial differential diagnoses from the patient history. While no one physical examination maneuver is completely accurate, in combination, multiple maneuvers increase in sensitivity and specificity.

Range of motion (ROM) is an important component of the physical examination. By comparing the extent of motion bilaterally, the clinician is able to appreciate side-to-side differences, which may indicate anterosuperior or posterosuperior rotator cuff tears. Additionally, muscle strength testing can isolate the injury to the anterosuperior rotator cuff in cases of internal rotational and abduction weakness or the posterosuperior rotator cuff in cases of external rotational and abduction weakness.

Subacromial impingement presents similarly to patients with true rotator cuff tears, often complaining of anterosuperior pain and weakness. Many studies have argued that subacromial impingement, along with subcoracoid impingement, and internal impingement may progress to rotator cuff tears, especially under continual stress [29 - 31 ]. Physical examination maneuvers such as the Neer Impingement sign and the Hawkins-Kennedy test are useful techniques for determining whether impingement is present. However, these techniques are not useful in determining whether the injury is a true rotator cuff tear rather than just impingement.

Specific provocative physical examination maneuvers have been developed to assess whether a rotator cuff tear is present and to determine its location. These tests serve to differentiate rotator cuff tear pathology from impingement or other pathology that might present similarly. As with other physical examination maneuvers, the sensitivity and specificity varies, but improves in combination. Each maneuver should be a component of the overall assessment of the patient's shoulder injury. Table 1 summarizes the sensitivities and specificities of physical examination maneuvers for detecting specific rotator cuff muscle tears.

Table 1. Summary of sensitivities and specificities of physical examination maneuves for detecting specific rotator cuff muscle tears.

\begin{tabular}{|c|c|c|c|c|c|}
\hline & & & Patients (n) & Sensitivity (\%) & Specificity (\%) \\
\hline \multirow{7}{*}{ Supraspinatus } & \multirow{2}{*}{ Rent Test } & Wolf et al. & 109 & 95.7 & 96.8 \\
\hline & & Lyons et al. & 42 & 91 & 75 \\
\hline & \multirow{3}{*}{ Jobe Test } & Park et al. & 215 & 52.6 & 82.4 \\
\hline & & Litaker et al. & 448 & 64 & 65 \\
\hline & & Itoi et al. & 143 & 89 & 98 \\
\hline & \multirow{2}{*}{ Drop Arm Sign } & Park et al. & 215 & 35 & 88 \\
\hline & & Murell et al. & 400 & 10 & 98 \\
\hline Infraspinatus & $\begin{array}{l}\text { External Rotation Lag } \\
\text { Sign }\end{array}$ & Castoldi et al. & 401 & 97 & 93 \\
\hline \multirow{4}{*}{ Subscapularis } & Belly-Press Test & Bartsch et al. & 50 & 86 & 91 \\
\hline & List-Off Test & Bartsch et al. & 50 & 40 & 79 \\
\hline & \multirow{2}{*}{ Bear Hug Test } & Yoon et al. & 312 & 19 & 91 \\
\hline & & Barth et al. & 58 & 60 & 91.7 \\
\hline \multirow{3}{*}{ Teres Minor } & Hornblower's Sign & Walch et al. & 54 & 94 & 100 \\
\hline & & & & & \\
\hline & $\begin{array}{l}\text { External Rotation Lag } \\
\text { Sign }\end{array}$ & Collin et al. & 100 & 100 & 92 \\
\hline
\end{tabular}




\section{Supraspinatus}

Supraspinatus rotator cuff tears are assessed with three physical examination maneuvers: the rent test, the Jobe test, and the drop arm sign. The rent test, originally described in 1934 by Codman, involves palpating the anterior insertion of the greater tuberosity to detect any crepitus, corresponding to supraspinatus deficiencies. With the patient's arm at his or her side in neutral position, the anterior portion of the supraspinatus insertion on the greater tuberosity is located under the anterolateral acromion just lateral to the coracoacromial ligament. The patient's arm is then moved through a range of internal and external rotation with slight abduction and extension. The few studies investigating the accuracy of the rent test have reported good results. Wolf et al. reported the rent test had a $95.7 \%$ sensitivity and $96.8 \%$ specificity for diagnosing full thickness rotator cuff tears in 109 consecutive patients [32]. Lyons et al. reported a 91\% sensitivity and a $75 \%$ specificity for diagnosing rotator cuff tears in 42 patients [33]. Both studies concluded that the rent test was overall beneficial in diagnosing rotator cuff tears.

The Jobe test is an additional maneuver, which assesses for asymmetric supraspinatus weakness against resistance. Both arms of the patient are passively placed in $90^{\circ}$ of abduction in the scapular plane with both thumbs facing downwards, the so called "empty can" position. The examiner then places an equal downward force on both forearms, while the patient resists. Differences in resistance strength are appreciated between the two arms. A level I study by Park et al. reported that the Jobe test had a $52.6 \%$ sensitivity and a $82.4 \%$ specificity for diagnosing full-thickness rotator cuff tears in 215 patients [34]. Additionally, they reported that the Jobe test had a $32.1 \%$ sensitivity and a $67.8 \%$ specificity for diagnosing partial-thickness rotator cuff tears in 72 patients. Litaker et al. investigated the accuracy of the Jobe test for diagnosing rotator cuff tears compared to arthrography in older patients [35]. They reported that in 448 consecutive patients with suspected rotator cuff tears, the Jobe test had a $64 \%$ sensitivity and a $65 \%$ specificity for diagnosing a full or partial thickness rotator cuff tear. Finally, Itoi et al. investigated the accuracy of the Jobe test compared to magnetic resonance imaging (MRI) for diagnosing a torn supraspinatus tendon [36]. They reported that in 143 shoulders, the Jobe test had a $89 \%$ sensitivity and a $98 \%$ specificity for diagnosing supraspinatus tears. Additionally, they noted that the Jobe test was more accurate when assessing weakness rather than pain. The sensitivity and specificity reported by Itoi et al. [36] differs tremendously from the sensitivity and specificity reported by Park et $a l$. [34] This may be due to differences in the number of patients and different diagnostic standards for calculating the accuracy of the Jobe test. Park et al. used arthroscopy as the diagnostic standard [34], while Itoi et al. used MRI [36]. It is plausible that additional asymptomatic rotator cuff tears were missed on MRI, which could bias the results. Overall, these studies demonstrate that the Jobe test has a wide range of accuracy; hence it is most useful in conjunction with other physical examination maneuvers.

The drop arm sign is an indication of a massive posterosuperior rotator cuff tear. The patient is asked to abduct and hold his or her arm at $90^{\circ}$. Patients unable to keep their arms abducted and resist the force of gravity often have a massive posterosuperior rotator cuff tear. Park et al. reported that the drop arm sign had a $35 \%$ sensitivity and a $88 \%$ specificity for diagnosing full-thickness rotator cuff tears in 215 patients, and $14.3 \%$ sensitive and $78 \%$ specific for diagnosing partial-thickness rotator cuff tears [34]. Murell et al. reported similar results, they found the drop arm sign to be $10 \%$ sensitive and $98 \%$ specific in 400 patients [37]. Additionally, they reported that a rotator cuff tear was present in $98 \%$ of cases when combining a positive drop arm sign with notable impingement and external rotational weakness.

\section{Infraspinatus}

External rotational deficits indicating infraspinatus injuries can be observed during general strength testing. However, often, external rotational strength testing will elicit pain and guarding. The external rotation lag sign tests for posterosuperior cuff tears without evoking pain from strength testing. The patient's elbow is flexed to $90^{\circ}$ with the arm left at his or her side. The arm is then passively moved to $20^{\circ}-30^{\circ}$ of external rotation. The inability to maintain the arm in the externally rotated position is an indication of posterosuperior cuff deficiency. The amount of internal rotational movement is noted. Castoldi et al. investigated the diagnostic accuracy of the external rotation lag sign in cases of isolated full-thickness supraspinatus tears, combined supraspinatus and infraspinatus full-thickness tears and combined supraspinatus, infraspinatus and teres minor full-thickness tears [38]. They reported that the sensitivity significantly increased, while the specificity slightly decreased in cases of combined posterosuperior rotator cuff tears $(97 \%$ sensitivity, $93 \%$ specificity) compared to isolated supraspinatus tears (56\% sensitivity, $98 \%$ specificity) (Table 1). While the specificity was marginally higher (5\%) for diagnosing isolated supraspinatus tears, the increase in sensitivity (41\%) for diagnosing combined supraspinatus and infraspinatus tears is far more significant. 


\section{Subscapularis}

Subscapularis injury can be first noted by internal rotation weakness during muscle strength testing. Additional maneuvers specific to the subscapularis include the Belly-Press test, the Lift-off test and the Bear Hug test. The BellyPress test involves the patient pressing down on his or her abdomen equally with both hands, with the elbows pointed laterally. In cases of subscapularis deficiency, the patient's elbow on the affected side will move posteriorly as ancillary musculature is recruited. The Lift-off test is another maneuver commonly used to investigate subscapularis injuries. The dorsal aspect of the patient's hand is placed on the lumbar spine and then passively lifted off the spine. When a patient is unable to maintain the position as his or her hand falls back to the spine, is considered a positive sign. Additionally a modified Lift-off test may be performed in the same position while the patient is asked to press against the clinician's hand. The amount of internal rotational resistance is compared to the unaffected side. Bartsch et al. investigated the diagnostic accuracy of an array of physical examination maneuvers for diagnosing subscapularis lesions [39]. They reported that the Belly-press test had the greatest sensitivity and specificity $(86 \%$ and $91 \%)$, while the Lift-off test had much lower sensitivity and specificity (40\% and 79\%). One explanation for the lower diagnostic accuracy of the Liftoff test is recruitment of surrounding musculature. An electromyographic study demonstrated that the Lift-off test was unable to isolate the subscapularis musculature from the teres major, latissimus dorsi, posterior deltoid, or rhomboid muscles [40]. Additionally, patients were able to perform the Lift-off test in subscapularis deficient states.

The Bear Hug test is an additional maneuver targeting potential subscapularis lesions [41, 42]. The patient places the palmar side of his or her hand of the affected arm on the contralateral acromioclavicular (AC) joint. The patient is asked to press down on the AC joint while keeping his or her elbow at the same height as his or her shoulder. A positive sign is considered when the patient is unable to maintain the elbow in line with the shoulder. Yoon et al. reported that the Bear Hug test had a $19 \%$ sensitivity and a $91 \%$ specificity for diagnosing full or partial thickness subscapularis tears in 312 patients who underwent subsequent shoulder arthroscopy [41]. Contrastingly, Barth et al. reported a $60 \%$ sensitivity and a $91.7 \%$ specificity in 58 patients who underwent subsequent arthroscopy [42]. While diagnostic accuracy differed between the two studies, both studies found the Bear Hug test to be highly specific and less sensitive. The Bear Hug test may be useful in cases where other tests are equivocal.

\section{Teres Minor}

Teres minor injuries are rarely isolated and are often an inferior extension of a posterosuperior rotator cuff tear. Rotator cuff tears involving the teres minor can be identified using the Hornblower's sign. The Hornblower's sign involves placing the injured arm in $90^{\circ}$ of abduction in the scapular plane. The patient then maximally externally rotates his or her arm with the elbow flexed to $90^{\circ}$. Patients with teres minor injuries will be unable to maintain the position and the injured arm will revert to an internally rotated position. Because most patients with teres minor injuries present with concurrent posterosuperior cuff tears, it may be necessary to provide abduction support beneath the elbow while performing the maneuver. Walch et al. found the Hornblower's sign had a $94 \%$ sensitivity and $100 \%$ specificity for diagnosing rotator cuff tears involving the teres minor in 54 patients [43]. However, Collin et al. found that an external rotation lag sign greater than $40^{\circ}$ was the most sensitive (100\%) and specific (92\%) for diagnosing teres minor lesions [44].

While reported diagnostic accuracies for specific physical examination maneuvers vary between studies, the most important conclusion is that specific maneuvers are an important component of the workup for rotator cuff tears. Furthermore, performing a series of specific maneuvers increases the overall diagnostic accuracy.

\section{CONCLUSION}

Rotator cuff tears are common, with many known risk factors. Older patients and those who perform strenuous overhead labor are at increased risk of injury. Furthermore, new research has demonstrated that certain genetic polymorphisms and anatomic bony configurations may also be risk factors. The critical shoulder angle is one important anatomic measure that may be modifiable when treating patients with rotator cuff tears. The rotator cuff serves to axially compress the humeral head in the glenohumeral joint and provide rotational motion. Functionally relevant injuries result when the force couples become unbalanced. Pain can be caused by a variety of factors such as tendinopathy, edge instability, superior migration, and long head biceps tendon instability. Specific physical examination maneuvers are an important part of the workup for any potential tear. The location of tear can be determined fairly accurately with a combined series of maneuvers. 


\section{CONFLICT OF INTEREST}

This research was supported by the Steadman Philippon Research Institute. The Institute receives research support from the following entities: Smith \& Nephew Endoscopy, Inc.; Arthrex, Inc.; Siemens Medical Solutions USA, Inc.; Ossur Americas, Inc.; Opedix, Inc. This work was not supported directly by outside funding or grants. Dr. Peter J. Millett has received from Arthrex something of value (exceeding the equivalent of US\$500) not related to this manuscript or research. He is a consultant and receives payments from Arthrex and has stock options in GameReady and Vumedi. Dr. Maximilian Petri had his research position at the Steadman Philippon Research institute funded by Arthrex. The other authors receive support from the Steadman Philippon Research Institute.

\section{ACKNOWLEDGEMENTS}

Declared none.

\section{REFERENCES}

[1] Hsu J, Keener JD. Natural history of rotator cuff disease and implications on management. Oper Tech Orthop 2015; 25(1): 2-9. [http://dx.doi.org/10.1053/j.oto.2014.11.006] [PMID: 26726288]

[2] Tashjian RZ. Epidemiology, natural history, and indications for treatment of rotator cuff tears. Clin Sports Med 2012; 31(4): 589-604. [http://dx.doi.org/10.1016/j.csm.2012.07.001] [PMID: 23040548]

[3] Gomoll AH, Katz JN, Warner JJ, Millett PJ. Rotator cuff disorders: recognition and management among patients with shoulder pain. Arthritis Rheum 2004; 50(12): 3751-61. [http://dx.doi.org/10.1002/art.20668] [PMID: 15593187]

[4] Bhatia S, Greenspoon JA, Horan MP, Warth RJ, Millett PJ. Two-year outcomes after arthroscopic rotator cuff repair in recreational athletes older than 70 years. Am J Sports Med 2015; 43(7): 1737-42. [http://dx.doi.org/10.1177/0363546515577623] [PMID: 25834140]

[5] Fehringer EV, Sun J, VanOeveren LS, Keller BK, Matsen FA III. Full-thickness rotator cuff tear prevalence and correlation with function and co-morbidities in patients sixty-five years and older. J Shoulder Elbow Surg 2008; 17(6): 881-5. [http://dx.doi.org/10.1016/j.jse.2008.05.039] [PMID: 18774738]

[6] Yamaguchi K, Ditsios K, Middleton WD, Hildebolt CF, Galatz LM, Teefey SA. The demographic and morphological features of rotator cuff disease. A comparison of asymptomatic and symptomatic shoulders. J Bone Joint Surg Am 2006; 88(8): 1699-704. [http://dx.doi.org/10.2106/JBJS.E.00835] [PMID: 16882890]

[7] Tempelhof S, Rupp S, Seil R. Age-related prevalence of rotator cuff tears in asymptomatic shoulders. J Shoulder Elbow Surg 1999; 8(4): 296-9.

[http://dx.doi.org/10.1016/S1058-2746(99)90148-9] [PMID: 10471998]

[8] Moosmayer S, Tariq R, Stiris M, Smith HJ. The natural history of asymptomatic rotator cuff tears: a three-year follow-up of fifty cases. J Bone Joint Surg Am 2013; 95(14): 1249-55. [http://dx.doi.org/10.2106/JBJS.L.00185] [PMID: 23864172]

[9] Mall NA, Kim HM, Keener JD, et al. Symptomatic progression of asymptomatic rotator cuff tears: a prospective study of clinical and sonographic variables. J Bone Joint Surg Am 2010; 92(16): 2623-33. [http://dx.doi.org/10.2106/JBJS.I.00506] [PMID: 21084574]

[10] Keener JD, Galatz LM, Teefey SA, et al. A prospective evaluation of survivorship of asymptomatic degenerative rotator cuff tears. J Bone Joint Surg Am 2015; 97(2): 89-98.

[http://dx.doi.org/10.2106/JBJS.N.00099] [PMID: 25609434]

[11] Namdari S, Donegan RP, Chamberlain AM, Galatz LM, Yamaguchi K, Keener JD. Factors affecting outcome after structural failure of repaired rotator cuff tears. J Bone Joint Surg Am 2014; 96(2): 99-105. [http://dx.doi.org/10.2106/JBJS.M.00551] [PMID: 24430408]

[12] Gwilym SE, Watkins B, Cooper CD, et al. Genetic influences in the progression of tears of the rotator cuff. J Bone Joint Surg Br 2009; 91(7): 915-7.

[http://dx.doi.org/10.1302/0301-620X.91B7.22353] [PMID: 19567856]

[13] Harvie P, Ostlere SJ, Teh J, et al. Genetic influences in the aetiology of tears of the rotator cuff. Sibling risk of a full-thickness tear. J Bone Joint Surg Br 2004; 86(5): 696-700. [http://dx.doi.org/10.1302/0301-620X.86B5.14747] [PMID: 15274266]

[14] Motta GdaR, Amaral MV, Rezende E, et al. Evidence of genetic variations associated with rotator cuff disease. J Shoulder Elbow Surg 2014; 23(2): 227-35. [http://dx.doi.org/10.1016/j.jse.2013.07.053] [PMID: 24129055]

[15] Spiegl UJ, Horan MP, Smith SW, Ho CP, Millett PJ. The critical shoulder angle is associated with rotator cuff tears and shoulder osteoarthritis and is better assessed with radiographs over MRI. Knee Surg Sports Traumatol Arthrosc 2015. [Epub ahead of print]. [http://dx.doi.org/10.1007/s00167-015-3587-7] [PMID: 25820655] 
[16] Moor BK, Röthlisberger M, Müller DA, et al. Age, trauma and the critical shoulder angle accurately predict supraspinatus tendon tears. Orthop Traumatol Surg Res 2014; 100(5): 489-94. [http://dx.doi.org/10.1016/j.otsr.2014.03.022] [PMID: 25012397]

[17] Gerber C, Snedeker JG, Baumgartner D, Viehöfer AF. Supraspinatus tendon load during abduction is dependent on the size of the critical shoulder angle: A biomechanical analysis. J Orthop Res 2014; 32(7): 952-7. [http://dx.doi.org/10.1002/jor.22621] [PMID: 24700399]

[18] Ames JB, Horan MP, Van der Meijden OA, Leake MJ, Millett PJ. Association between acromial index and outcomes following arthroscopic repair of full-thickness rotator cuff tears. J Bone Joint Surg Am 2012; 94(20): 1862-9. [http://dx.doi.org/10.2106/JBJS.K.01500] [PMID: 23079878]

[19] Nyffeler RW, Werner CM, Sukthankar A, Schmid MR, Gerber C. Association of a large lateral extension of the acromion with rotator cuff tears. J Bone Joint Surg Am 2006; 88(4): 800-5. [http://dx.doi.org/10.2106/JBJS.D.03042] [PMID: 16595470]

[20] Gill TJ, McIrvin E, Kocher MS, Homa K, Mair SD, Hawkins RJ. The relative importance of acromial morphology and age with respect to rotator cuff pathology. J Shoulder Elbow Surg 2002; 11(4): 327-30. [http://dx.doi.org/10.1067/mse.2002.124425] [PMID: 12195249]

[21] Burkhart SS. Arthroscopic treatment of massive rotator cuff tears. Clinical results and biomechanical rationale. Clin Orthop Relat Res 1991; (267): 45-56.

[PMID: 2044292]

[22] Warner JJ, Higgins L, Parsons IM IV, Dowdy P. Diagnosis and treatment of anterosuperior rotator cuff tears. J Shoulder Elbow Surg 2001; 10(1): 37-46. [http://dx.doi.org/10.1067/mse.2001.112022] [PMID: 11182734]

[23] Parsons IM, Apreleva M, Fu FH, Woo SL. The effect of rotator cuff tears on reaction forces at the glenohumeral joint. J Orthop Res 2002; 20(3): 439-46. [http://dx.doi.org/10.1016/S0736-0266(01)00137-1] [PMID: 12038616]

[24] Burkhart SS. Arthroscopic debridement and decompression for selected rotator cuff tears. Clinical results, pathomechanics, and patient selection based on biomechanical parameters. Orthop Clin North Am 1993; 24(1): 111-23. [PMID: 8421604]

[25] Hansen ML, Otis JC, Johnson JS, Cordasco FA, Craig EV, Warren RF. Biomechanics of massive rotator cuff tears: implications for treatment. J Bone Joint Surg Am 2008; 90(2): 316-25. [http://dx.doi.org/10.2106/JBJS.F.00880] [PMID: 18245591]

[26] von Wehren L, Blanke F, Todorov A, Heisterbach P, Sailer J, Majewski M. The effect of subacromial injections of autologous conditioned plasma versus cortisone for the treatment of symptomatic partial rotator cuff tears. Knee Surg Sports Traumatol Arthrosc 2015. [Epub ahead of print]. [http://dx.doi.org/10.1007/s00167-015-3651-3] [PMID: 26017742]

[27] Keener JD, Wei AS, Kim HM, Steger-May K, Yamaguchi K. Proximal humeral migration in shoulders with symptomatic and asymptomatic rotator cuff tears. J Bone Joint Surg Am 2009; 91(6): 1405-13. [http://dx.doi.org/10.2106/JBJS.H.00854] [PMID: 19487518]

[28] Creech MJ, Yeung M, Denkers M, Simunovic N, Athwal GS, Ayeni OR. Surgical indications for long head biceps tenodesis: a systematic review. Knee Surg Sports Traumatol Arthrosc 2014. [Epub ahead of print]. [http://dx.doi.org/10.1007/s00167-014-3383-9] [PMID: 25416963]

[29] Neer CS II. Impingement lesions. Clin Orthop Relat Res 1983; (173): 70-7. [PMID: 6825348]

[30] Tyson LL, Crues JV III. Pathogenesis of rotator cuff disorders. Magnetic resonance imaging characteristics. Magn Reson Imaging Clin N Am 1993; 1(1): 37-46. [PMID: 7584213]

[31] Hyvönen P, Lohi S, Jalovaara P. Open acromioplasty does not prevent the progression of an impingement syndrome to a tear. Nine-year follow-up of 96 cases. J Bone Joint Surg Br 1998; 80(5): 813-6. [http://dx.doi.org/10.1302/0301-620X.80B5.8533] [PMID: 9768891]

[32] Wolf EM, Agrawal V. Transdeltoid palpation (the rent test) in the diagnosis of rotator cuff tears. J Shoulder Elbow Surg 2001; 10(5): 470-3. [http://dx.doi.org/10.1067/mse.2001.117126] [PMID: 11641706]

[33] Lyons AR, Tomlinson JE. Clinical diagnosis of tears of the rotator cuff. J Bone Joint Surg Br 1992; 74(3): 414-5. [PMID: 1587891]

[34] Park HB, Yokota A, Gill HS, El Rassi G, McFarland EG. Diagnostic accuracy of clinical tests for the different degrees of subacromial impingement syndrome. J Bone Joint Surg Am 2005; 87(7): 1446-55. [http://dx.doi.org/10.2106/JBJS.D.02335] [PMID: 15995110]

[35] Litaker D, Pioro M, El Bilbeisi H, Brems J. Returning to the bedside: using the history and physical examination to identify rotator cuff tears. J Am Geriatr Soc 2000; 48(12): 1633-7. 
[http://dx.doi.org/10.1111/j.1532-5415.2000.tb03875.x] [PMID: 11129754]

[36] Itoi E, Kido T, Sano A, Urayama M, Sato K. Which is more useful, the "full can test" or the "empty can test," in detecting the torn supraspinatus tendon? Am J Sports Med 1999; 27(1): 65-8.

[PMID: 9934421]

[37] Murrell GA, Walton JR. Diagnosis of rotator cuff tears. Lancet 2001; 357(9258): 769-70. [http://dx.doi.org/10.1016/S0140-6736(00)04161-1] [PMID: 11253973]

[38] Castoldi F, Blonna D, Hertel R. External rotation lag sign revisited: accuracy for diagnosis of full thickness supraspinatus tear. J Shoulder Elbow Surg 2009; 18(4): 529-34.

[http://dx.doi.org/10.1016/j.jse.2008.11.007] [PMID: 19223205]

[39] Bartsch M, Greiner S, Haas NP, Scheibel M. Diagnostic values of clinical tests for subscapularis lesions. Knee Surg Sports Traumatol Arthrosc 2010; 18(12): 1712-7. [http://dx.doi.org/10.1007/s00167-010-1109-1] [PMID: 20376624]

[40] Stefko JM, Jobe FW, VanderWilde RS, Carden E, Pink M. Electromyographic and nerve block analysis of the subscapularis liftoff test. J Shoulder Elbow Surg 1997; 6(4): 347-55. [http://dx.doi.org/10.1016/S1058-2746(97)90002-1] [PMID: 9285874]

[41] Yoon JP, Chung SW, Kim SH, Oh JH. Diagnostic value of four clinical tests for the evaluation of subscapularis integrity. J Shoulder Elbow Surg 2013; 22(9): 1186-92.

[http://dx.doi.org/10.1016/j.jse.2012.12.002] [PMID: 23434234]

[42] Barth JR, Burkhart SS, De Beer JF. The bear-hug test: a new and sensitive test for diagnosing a subscapularis tear. Arthroscopy 2006; 22(10): 1076-84. [http://dx.doi.org/10.1016/j.arthro.2006.05.005] [PMID: 17027405]

[43] Walch G, Boulahia A, Calderone S, Robinson AH. The 'dropping' and 'hornblower's' signs in evaluation of rotator-cuff tears. J Bone Joint Surg Br 1998; 80(4): 624-8. [http://dx.doi.org/10.1302/0301-620X.80B4.8651] [PMID: 9699824]

[44] Collin P, Treseder T, Denard PJ, Neyton L, Walch G, Lädermann A. What is the best clinical test for assessment of the teres minor in massive rotator cuff tears? Clin Orthop Relat Res 2015; 473(9): 2959-66. [http://dx.doi.org/10.1007/s11999-015-4392-9] [PMID: 26066066]

(C) Moulton et al.; Licensee Bentham Open.

This is an open access article licensed under the terms of the Creative Commons Attribution-Non-Commercial 4.0 International Public License (CC BY-NC 4.0) (https://creativecommons.org/licenses/by-nc/4.0/legalcode), which permits unrestricted, non-commercial use, distribution and reproduction in any medium, provided the work is properly cited. 